(2) Open Access Full Text Article

\title{
Dexmedetomidine for awake intubation and an opioid-free general anesthesia in a superobese patient with suspected difficult intubation
}

This article was published in the following Dove Press journal:

Drug Design, Development and Therapy

7 July 2014

Number of times this article has been viewed

\section{Tomasz Gaszynski' \\ Ewelina Gaszynska² \\ Tomasz Szewczyk ${ }^{3}$}

'Department of Anesthesiology and Intensive Therapy, ${ }^{2}$ Department of Hygiene and Health Promotion, ${ }^{3}$ Department of Gastroenterology, Oncology, and General Surgery, Barlicki University Hospital, Medical University of Lodz, Poland
Correspondence: Tomasz Gaszynski Department of Emergency Medicine and Disaster Medicine, Medical University of Lodz, Poland, Barlicki University Hospital, ul Kopcinskiego 22, 90-I 53 Lodz, Poland Fax +48 426783748

Email tomasz.gaszynski@umed.lodz.pl

\begin{abstract}
Super-obese patients (body mass index [BMI] $>50 \mathrm{~kg} / \mathrm{m}^{2}$ ) are at a particularly high risk of anesthesia-related complications during postoperative period, eg, critical respiratory events including respiratory arrest, and over-sedation leading to problems with maintaining airway open, hypoxia and hypercapnia. In this paper authors present a case of a 39-year-old super-obese (BMI $62.3 \mathrm{~kg} / \mathrm{m}^{2}$ ) female patient who was admitted for surgical treatment of obesity. Preanesthesia evaluation revealed hypertension and type 2 diabetes mellitus (DM) as comorbidities as well as potential for a difficult intubation- neck circumference of $46 \mathrm{~cm}$, reduced neck mobility and DM type 2. Patient was intubated using "awake intubation" method using topical anesthesia and dexmedetomidine infusion. General anesthesia was maintained with sevoflurane and dexmedetomidine infusion instead of opioid administration in "opioidfree anesthesia method".
\end{abstract}

Keywords: morbid obesity, non-opioid anesthesia, dexmedetomidine

\section{Introduction}

Superobese patients (body mass index [BMI] $>50 \mathrm{~kg} / \mathrm{m}^{2}$ ) are at a particularly high risk of anesthesia-related complications during the postoperative period (eg, critical respiratory events [CRE] including respiratory arrest, as well as oversedation leading to problems with maintaining the airway open, hypoxia, and hypercapnia). ${ }^{1}$ Therefore, anesthetic management of these patients should be focused on preventing them from possible respiratory complications.

In this article, we present a case of a superobese 39-year-old female patient who was admitted to Barlicki University Hospital in Lodz, Poland, for surgical treatment of obesity and scheduled for laparoscopic gastric banding. The patient gave consent for this publication. Her BMI, weight, and height were $62.3 \mathrm{~kg} / \mathrm{m}^{2}, 180 \mathrm{~kg}$, and $170 \mathrm{~cm}$, respectively. Her ideal body weight (IBW) of $65 \mathrm{~kg}$ was calculated according to the following formula: IBW $=$ height -105 . Preanesthesia evaluation revealed hypertension and type 2 diabetes mellitus as comorbidities, as well as potential for a difficult intubation: neck circumference of $46 \mathrm{~cm}$, reduced neck mobility, and diabetes mellitus type $2 .^{2}$ The patient was positioned on a pillow facilitating intubation in morbidly obese individuals (Troop Elevation Pillow; Mercury Medical, Clearwater, FL, USA) and standard anesthesia monitoring was installed. Intravenous premedication consisted of atropine $0.5 \mathrm{mg}$, midazolam $2 \mathrm{mg}$, ondansetron $4 \mathrm{mg}$, and a $1 \mu \mathrm{g} / \mathrm{kg}$ IBW loading dose of dexmedetomidine delivered over 10 minutes.

After prolonged preoxygenation ( $>3$ minutes) and topical anesthesia with $2 \%$ lidocaine, the endotracheal intubation was attempted using IntuBrite videolaryngoscope (IntuBrite, 
Vista, CA, USA) with a pediatric handle and number 3 Macintosh blade. After successful intubation on the first attempt, general anesthesia was induced with $200 \mathrm{mg}$ propofol intravenously. A $0.6 \mathrm{mg} / \mathrm{kg}$ IBW of rocuronium for muscle relaxation was administered and confirmed by stimulation with a TOF-Guard device (Merck \& Co, Inc., Whitehouse Station, NJ, USA). Anesthesia was initially maintained with sevoflurane $1.1-1.3$ vol\% delivered in a mixture of air and oxygen. Dexmedetomidine infusion was set at a rate of $0.5 \mathrm{mcg} / \mathrm{kg}$ IBW per hour before the first skin incision. The depth of anesthesia was continuously evaluated with a Cerebral State Monitor device (Danmeter, Odense, Denmark). End-tidal concentration of sevoflurane was adjusted to maintain a Cerebral State Monitor value between 40 and 60. Trochar insertion sites were anesthetized locally by the surgeon. During the procedure, the patient remained hemodynamically stable. There were no episodes of hyper- or hypotension. This was achieved with the adjustment of the dexmedetomidine infusion rate, which ranged from $0.5 \mu \mathrm{g} / \mathrm{kg}$ IBW/hour to $1 \mu \mathrm{g} / \mathrm{kg}$ IBW per hour. No additional dose of opioid was administered. A single $20 \mathrm{mg}$ maintenance dose of rocuronium was administered intravenously. For postoperative analgesia, the patient received $100 \mathrm{mg}$ ketoprofen. At the end of the operation, $200 \mathrm{mg}$ sugammadex ( $2 \mathrm{mg} / \mathrm{kg}$ corrected body weight $)^{3,4}$ was given intravenously to reverse neuromuscular blockade, and after 3 minutes, the administration of sevoflurane and dexmedetomidine was stopped. Within 5 minutes, the patient emerged from anesthesia in the operating theatre and was extubated. Total anesthesia time was 45 minutes, and the total dose of dexmedetomidine given was $72 \mu \mathrm{g}$. At the moment she was transferred to the postanesthesia care unit (10 minutes after emergence), the patient reached 10 points in Aldrete score. The postoperative period was uneventful, and the patient did not require opioids for pain management. Postoperative pain evaluated using a visual analog scale was less than 4. Multimodal analgesia was used with ketoprofen and paracetamol, effectively. ${ }^{5}$

\section{Discussion}

Opioid-free and low opioid anesthesia may be indicated for patients in whom respiratory complications in the postoperative period are most common. In the superobese, the probability of CRE should be considered. ${ }^{1}$ The adverse effects of using opioids in morbidly obese patients in the recovery room and first postoperative day include not only respiratory complications but also increased postoperative nausea and vomiting and digestive tract complications. ${ }^{6}$ One strategy to avoid or minimize the intraoperative use of opioids, and therefore reduce the risk of adverse effects and possible complications of opioids, is to administer dexmedetomidine. Tufanogullari et al conducted a dosing study on dexmedetomidine in the morbidly obese. ${ }^{7}$ They administered dexmedetomidine in doses ranging from 0.2 to $0.8 \mu \mathrm{g} / \mathrm{kg}$ total body weight (TBW) per hour. They observed that a dose of $0.2 \mu \mathrm{g} / \mathrm{kg}$ TBW per hour should not result in any hemodynamic disturbances. The dosing regimen we used was $0.5-1.0 \mu \mathrm{g} / \mathrm{kg} / \mathrm{IBW}$ per hour and is an established dose for procedural sedation, as indicated by one of the drug's manufacturers (Hospira, Lake Forest, IL, USA). Infusion of dexmedetomidine reduces the use of fentanyl during bariatric surgery. ${ }^{8}$ In our case, it eliminated the need for intraoperative opioid administration at all. Mansour et al conducted a study in morbidly obese patients comparing opioid-free anesthesia using ketamine with an opioid-based anesthesia using a fentanyl infusion. ${ }^{9}$ They observed that opioid-free anesthesia is effective and safe for bariatric surgery. Hofer et al reported a similar case to ours in a superobese patient, but they intubated the patient using a fiberscope in the awake intubation technique, using midazolam and ketamine, and dexmedetomidine infusion was commenced after induction of anesthesia. ${ }^{10}$ They conducted general anesthesia without opioids, using an isoflurane and dexmedetomidine infusion. In our case, and in the Hofer case, it was possible to resign from opioid administration completely because of the use of dexmedetomidine.

It has also been established that intraoperative infusion of dexmedetomidine reduces opioid requirement for postoperative analgesia in morbidly obese patients. ${ }^{11}$ We decided not to use opioids in the postoperative period and to administer nonsteroidal anti-inflammatory drugs instead, as laparoscopic gastric banding is not associated with major postoperative pain. For the presented patient, nonsteroidal anti-inflammatory drugs proved to be sufficient for pain management. ${ }^{5}$ ZiemannGimmel et al reported that opioid-free anesthesia with dexmedetomidine is associated with a large reduction in relative risk for postoperative nausea and vomiting. ${ }^{6}$

Our case is also the first presentation of the successful use of the Intubrite videolaryngoscope in a superobese patient for awake intubation, using dexmedetomidine. The Intubrite laryngoscope was designed to aid in difficult intubation. The Intubrite laryngoscope blade is a patented design using a unique black light illumination source (in addition to a white, light-emitting diode illuminator) to enhance visualization of the vocal cords during intubation efforts. The black light technology causes the vocal cords to brightly phosphoresce. We used a pediatric handle of the Intubrite laryngoscope because of its short handle, which is very useful in the management of 


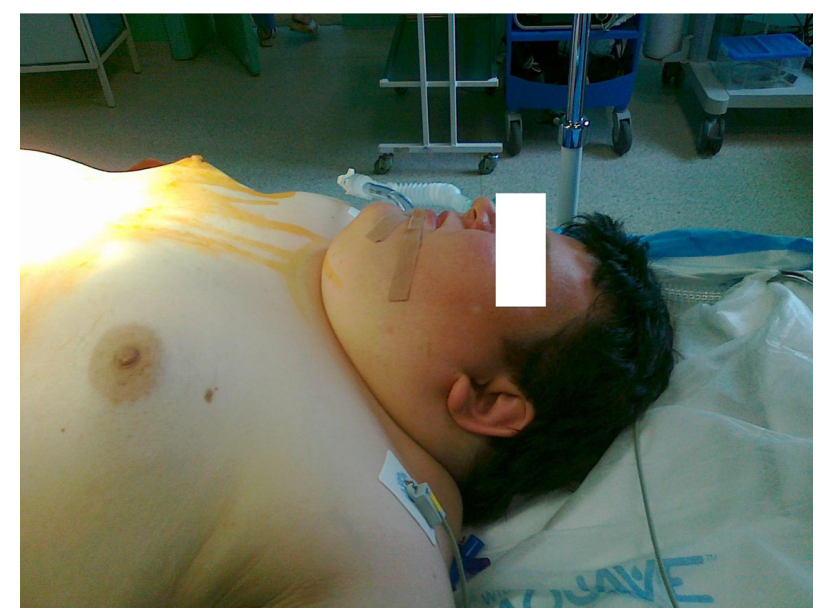

Figure I Airway evaluation of the patient revealed increased neck circumflex $(>46 \mathrm{~cm})$ and reduced neck mobility, which, together with a history of diabetes mellitus type 2 , indicated possible difficult intubation.

a predicted difficult intubation in morbidly obese patients. ${ }^{12}$ In the described case, we decided to conduct awake intubation because the patient had three important factors influencing the possibility of a difficult intubation: neck circumflex greater than $40 \mathrm{~cm}$, diabetes mellitus, and superobesity. ${ }^{3,13}$

In morbidly obese patients, use of an awake intubation technique and videolaryngoscope is recommended. ${ }^{14}$ There are several studies on the use of dexmedetomidine in an awake intubation procedure. Dexmedetomidine infusion allows the patient to breathe in a spontaneous respiratory pattern during awake intubation. Successful use of dexmedetomidine for awake fiberoptic intubation in morbidly obese patients is described in the literature. ${ }^{15-18}$ Abdelmalak et al performed awake fiberoptic intubation using dexmedetomidine as the sole sedative in morbidly obese patients with a critical airway. ${ }^{15}$ Sedation was initiated in the operating room, with an infusion of dexmedetomidine beginning with a loading dose of $1 \mu \mathrm{g} / \mathrm{kg}$ for 10 minutes, followed by a maintenance infusion of $0.6 \mu \mathrm{g} /(\mathrm{kg} \cdot \mathrm{hour})$. Topicalization of the oropharynx was accomplished with nebulized $4 \%$ lidocaine and $2 \%$ lidocaine gel. When using dexmedetomidine for awake fiberoptic intubation, some adverse effects are reported; these include hypotension and bradycardia. To avoid bradycardia, administration of glycopyrrolate $0.1 \mathrm{mg}$ is advised, and hypotension may be managed by phenylephrine and ephedrine boluses.

We conclude that dexmedetomidine may help minimize or eliminate intraoperative use of opioids in bariatric surgery, thus improving the safety profile in the postoperative period.

\section{References}

1. Gaszynski T, Jakubiak J, Machala W. Występowanie resztkowego zwiotczenia u pacjentów z otyłością znacznego stopnia i jego wpływ na przebieg okresu pooperacyjnego - ocena obecnie stosowanej praktyki [The Post-Operative Residual Curarisation among morbidly obese patients and its influence on postoperative period - evaluation of present practice]. Anesth Rescue. 2012;6:33-40. Polish.

2. Gaszynski T. Standard clinical tests for predicting difficult intubation are not useful among morbidly obese patients. Anesth Analg. 2004;99(3):956.

3. Gaszynski T, Szewczyk T, Gaszynski W. Randomized comparison of sugammadex and neostigmine for reversal of rocuronium-induced muscle relaxation in morbidly obese undergoing general anaesthesia. Br J Anaesth. 2012;108(2):236-239.

4. Sokół-Kobielska E. Sugammadex - indications and clinical use Anaesthesiol Intensive Ther. 2013;45(2):111-115.

5. Schumann R, Shikora S, Weiss JM, Wurm H, Strassels S, Carr DB. A comparison of multimodal perioperative analgesia to epidural pain management after gastric bypass surgery. Anesth Analg. 2003;96(2): 469-474.

6. Ziemann-Gimmel P, Goldfarb AA, Koppman J, Marema RT. Opioid-free total intravenous anaesthesia reduces postoperative nausea and vomiting in bariatric surgery beyond triple prophylaxis. $\mathrm{Br} J$ Anaesth. 2014;112(5):906-911.

7. Tufanogullari B, White PF, Peixoto MP, et al. Dexmedetomidine infusion during laparoscopic bariatric surgery: the effect on recovery outcome variables. Anesth Analg. 2008;106(6):1741-1748.

8. Bakhamees HS, El-Halafawy YM, El-Kerdawy HM, Gouda NM, Altemyatt S. Effects of dexmedetomidine in morbidly obese patients undergoing laparoscopic gastric bypass. Middle East J Anesthesiol. 2007;19(3):537-551.

9. Mansour MA, Mahmoud AA, Geddawy M. Nonopioid versus opioid based general anesthesia technique for bariatric surgery: A randomized double-blind study. Saudi J Anaesth. 2013;7(4):387-391.

10. Hofer RE, Sprung J, Sarr MG, Wedel DJ. Anesthesia for a patient with morbid obesity using dexmedetomidine without narcotics. Can J Anaesth. 2005;52(2):176-180.

11. Feld JM, Hoffman WE, Stechert MM, Hoffman IW, Ananda RC. Fentanyl or dexmedetomidine combined with desflurane for bariatric surgery. J Clin Anesth. 2006;18(1):24-28.

12. Gaszyński T. Clinical experience with the C-Mac videolaryngoscope in morbidly obese patients. Anaesthesiol Intensive Ther. 2014;46(1): 14-16.

13. Mashour GA, Kheterpal S, Vanaharam V, et al. The extended Mallampati score and a diagnosis of diabetes mellitus are predictors of difficult laryngoscopy in the morbidly obese. Anesth Analg. 2008;107(6):1919-1923.

14. Pelosi P, Gregoretti C. Perioperative management of obese patients. Best Pract Res Clin Anaesthesiol. 2010;24(2):211-225.

15. Abdelmalak B, Makary L, Hoban J, Doyle DJ. Dexmedetomidine as sole sedative for awake intubation in management of the critical airway. J Clin Anesth. 2007;19(5):370-373.

16. Grant SA, Breslin DS, MacLeod DB, Gleason D, Martin G. Dexmedetomidine infusion for sedation during fiberoptic intubation: a report of three cases. J Clin Anesth. 2004;16(2):124-126.

17. Bergese SD, Khabiri B, Roberts WD, Howie MB, McSweeney TD, Gerhardt MA. Dexmedetomidine for conscious sedation in difficult awake fiberoptic intubation cases. J Clin Anesth. 2007;19(2): 141-144.

18. Nagashima M, Kunisawa T, Takahata O, Iwasaki H. [Dexmedetomidine infusion for sedation during awake intubation]. Masui. 2008;57(6): 731-734. Japanese.

\section{Disclosure}

The authors report no conflicts of interest in this work. 


\section{Publish your work in this journal}

Drug Design, Development and Therapy is an international, peerreviewed open-access journal that spans the spectrum of drug design and development through to clinical applications. Clinical outcomes, patient safety, and programs for the development and effective, safe, and sustained use of medicines are a feature of the journal, which

has also been accepted for indexing on PubMed Central. The manuscript management system is completely online and includes a very quick and fair peer-review system, which is all easy to use. Visit http://www.dovepress.com/testimonials.php to read real quotes from published authors.

Submit your manuscript here: http://www.dovepress.com/drug-design-development-and-therapy-journal 